\title{
Unique nucleolar dominance patterns in distant hybrid lineage derived from Megalobrama Amblycephala $\times$ Culter Alburnus
}

\author{
Jun Xiao ${ }^{\dagger}$, Fangzhou Hu${ }^{\dagger}$, Kaikun Luo ${ }^{\dagger}$, Wuhui Li and Shaojun Liu ${ }^{*}$
}

\begin{abstract}
Background: Nucleolar dominance is an epigenetic phenomenon that occurs in interspecific hybrids and involves the expression of $45 S$ rRNA genes inherited from one progenitor due to the silencing of the other progenitor's rRNA genes. In this paper, changes in the genetics and expression of $45 \mathrm{~S}$ rRNA genes in F1 and F2 hybrid progeny of blunt snout bream (BSB, Megalobrama amblycephala) $\times$ topmouth culter (TC, Culter alburnus) are investigated.

Results: The 45S rDNA loci were analyzed by cloning, RT-PCR and sequencing methods. The results show that nucleolar dominance patterns differ in the F1 and F2 hybrids. In the F1 hybrids of BSB $\times T C$, all the tested individuals inherited and expressed the $45 \mathrm{~S}$ rRNA genes of both BSB and TC, indicating that nucleolar dominance is not established in the F1 hybrids. However, in the F2 hybrids of BSB $\times$ TC, five patterns are observed. Pattern 1 inherits and expresses only the $45 S$ rRNA gene of BSB. Pattern 2 inherits the $45 S$ rRNA gene from both BSB and TC, but only expresses the $45 S$ rRNA of BSB. Pattern 3 inherits and expresses the $45 \mathrm{~S}$ rRNA gene from both BSB and TC. Pattern 4 inherits the $45 S$ rRNA gene from both BSB and TC, but only expresses the 45S rRNA gene of TC. Pattern 5 inherits and expresses only the $45 \mathrm{~S}$ rRNA gene of TC.
\end{abstract}

Conclusions: Nucleolar dominance shows distinctive patterns in intergeneric hybrids of BSB $\times$ TC. It is not established in $\mathrm{F} 1$ hybrids and is random in F2 hybrids. This study provides new insights into the phenomenon of nucleolar dominance in genetic hybrids in vertebrates.

Keywords: Nucleolar dominance pattern, Distant hybrid lineage, 45S rRNA gene, SNP

\section{Background}

In eukaryotes, $45 \mathrm{~S}$ rRNA genes are tandemly arrayed by the hundreds, and sometimes by the thousands, at chromosomal loci spanning millions of base pairs. rRNA genes are transcribed by RNA polymerase I ( $\mathrm{Pol}$ I) into a precursor RNA (prerRNA) that encodes the three largest RNA components of ribosomes $[1,2]$. Nucleolar dominance is an epigenetic phenomenon that occurs in genetic hybrids and involves expression of the 45S rRNA genes inherited from only one progenitor. It has been revealed that nucleolar dominance is caused by the silencing of the other

\footnotetext{
* Correspondence: Isj@hunnu.edu.cn

${ }^{\dagger}$ Equal contributors

Key Laboratory of Protein Chemistry and Fish Developmental Biology of the Education Ministry of China, College of Life Sciences, Hunan Normal

University, Changsha 410081, People's Republic of China
}

progenitor's rRNA genes [3]. Ribosomal RNA gene silencing involves changes in DNA methylation and histone modifications [4-8]. But the molecular basis for the determination of which progenitor's genes are silenced remains unclear. Nucleolar dominance is first described in plants [9] and is widely observed in interspecific hybrids of plants, invertebrates, frogs, flies, fish and mammals [10, 11]. However, it has rarely been reported in different generations of hybrid lineages at the level of intergeneric hybridization in vertebrates because the formation of distant hybrid lineages in animals is challenging in practice.

The genetics and expression of $45 \mathrm{~S}$ rRNA genes have been studied by detecting single nucleotide polymorphism (SNP) sites in the 18S rRNA gene [12]. DNA sequencing, while relatively laborious, is the gold standard in SNP 
Table 1 The frequency distribution of the 5 different genetic expression patterns of $45 \mathrm{~S}$ rRNA gene in the $F_{2}$ hybrids

\begin{tabular}{lll}
\hline & Number & Percent \\
\hline Pattern1 $^{\text {a }}$ & 3 & $10 \%$ \\
Pattern2 $^{\text {a }}$ & 7 & $23.3 \%$ \\
Pattern3 $^{\text {a }}$ & 13 & $43.4 \%$ \\
Pattern4 $^{\text {a }}$ & 3 & $10 \%$ \\
Pattern5 $^{\text {a }}$ & 4 & $13.3 \%$ \\
Total & 30 & $100 \%$
\end{tabular}

${ }^{a}$ Note: Pattern 1 inherits and expresses the single 45S rRNA gene of BSB. Pattern 2 inherits both the 45S rRNA gene from BSB and TC, but only expresses the 45S rRNA of BSB. Pattern 3 inherits and expresses both the $45 \mathrm{~S}$ rRNA gene from BSB and TC. Pattern 4 inherits both the 45S rRNA gene from BSB and TC, but only expresses the $45 \mathrm{~S}$ rRNA gene of TC. Pattern 5 inherits and expresses the single $45 \mathrm{~S}$ rRNA gene of TC

discovery. The most widely used approach is direct DNA sequencing of polymerase chain reaction (PCR) products with dye-terminator chemistry analyzed on automated DNA sequencers [13]. SNPs are easily detected because two peaks are observed in sequence traces in the heterozygous state, compared with a single peak in the homozygous state.

In this study, based on the formation of a bisexual fertile hybrid lineage of blunt snout bream (BSB, Megalobrama amblycephala) $\times$ topmouth culter (TC, culter alburnus) [14], we analyze the genetics and expression patterns of $45 \mathrm{~S}$ rRNA genes in F1 and F2 hybrids. The results show that the genetics and expression patterns of $45 \mathrm{~S}$ rRNA genes in the liver of mature individuals differ in F1 and F2 hybrids. Furthermore, the parental $45 \mathrm{~S}$ rDNA to be silenced appears to be chosen randomly in the F2 hybrids of $\mathrm{BSB} \times \mathrm{TC}$, contrary to previous reports $[3,15,16]$. This study provides new insights into the phenomenon of nucleolar dominance in genetic hybrids in vertebrates. The hybrid lineages derived from $\mathrm{BSB} \times \mathrm{TC}$ provide good material with which to study the mechanism of nucleolar dominance.

\section{Results}

ITS1 sequence in parental species and hybrids

The PCR results of ITS1 sequences in BSB, TC and F1 and F2 hybrids of $\mathrm{BSB} \times \mathrm{TC}$ are shown in Fig. 1 (for every pattern of each kind of fish, one sample was used to present). In BSB, the ITS1 sequence is homogeneous and $322 \mathrm{bp}$ in length (DDBJ, accession number: AB872813) and similarly in TC the ITS1 sequence is homogeneous but $366 \mathrm{bp}$ in length (DDBJ, accession number: AB872814). The lengths of the fragments (including partial 18S rDNA, complete ITS1 rDNA and partial 5.8S rDNA sequences) amplified by primers P4F/ P4A in BSB (441 bp) and TC (487 bp) are clearly differentiated by electrophoresis in $2 \%$ agarose gel. Therefore, the fragments can be used as a simple genetic marker to examine the genetic heterogeneity of hybrid progeny of

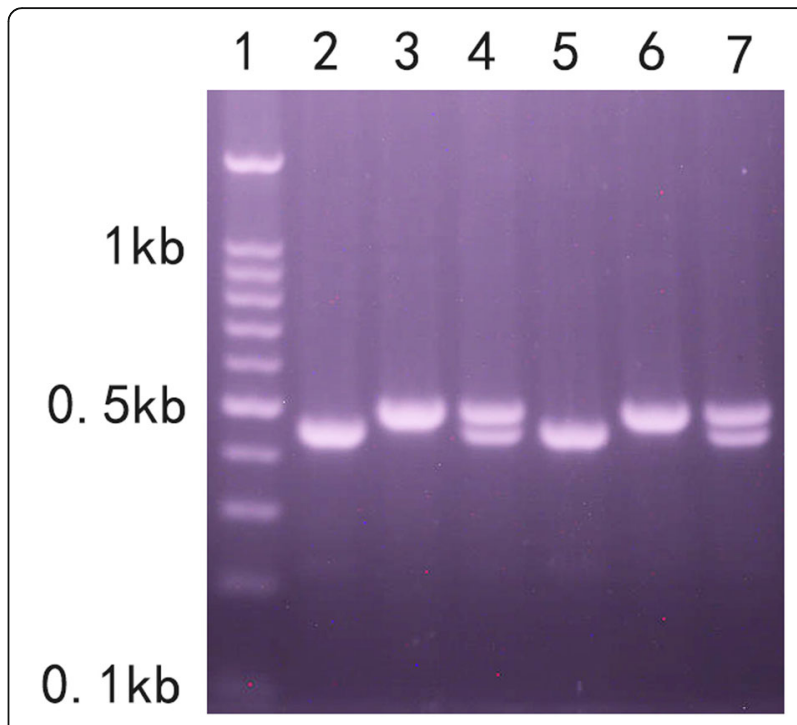

Fig. 1 The genotype of ITS1 in the four kinds of fish. Channel 1: $0.1 \mathrm{~kb}$ DNA grad mark. Channel 2: PCR results of ITS1 in BSB. Channel 3: PCR results of ITS1 in TC. Channel 4: PCR results of ITS1 in $F_{1}$ hybrids of $B S B \times T C$. Channel 5-7: PCR results of ITS1 in $F_{2}$ hybrids of $B S B \times T C$

BSB and TC. As shown in Fig. 1, only one kind of ITS1 genotype is found in the F1 hybrids, in which both parents' ITS1 bands are detected (Fig. 1). However, three kinds of genotypes are found in the F2 hybrids. Some individuals inherit the single ITS1 genotype of either BSB or TC, while others inherit both genotypes.

\section{Sequence and variation of 18S rRNA genes in parental species}

Sequence divergence between $18 \mathrm{~S}$ rDNA fragments amplified from BSB and TC with the 18S P1F/P1R primer pair is low. We examined intra- and interspecific sequence divergence for 60 sequences from $30 \mathrm{BSB}$ individuals and 60 sequences from $30 \mathrm{TC}$ individuals, consisting of $1565 \mathrm{bp}$ of the 18S rRNA gene. These sequences show 100\% similarity between BSB and TC except for a single SNP at position 40, which is fixed for cytosine in BSB and thymine in TC (Additional file 1).

\section{Expression of 45S rRNA}

The expression of $18 \mathrm{~S}$ rRNA was examined in BSB, TC and F1 and F2 hybrids of BSB $\times$ TC using genomic DNA from $\mathrm{BSB}$ as template in the PCR positive control and $\mathrm{ddH}_{2} \mathrm{O}$ as template in the PCR negative control. Thirty samples were tested from each kind of fish (BSB, TC, $\mathrm{F}_{1}$ and $\mathrm{F}_{2}$ ). Figure 2 shows the $18 \mathrm{~S}$ rRNA expression in each kind of fish (for every pattern of each kind of fish, one sample was used to present). After digestion with DNase I (Invitrogen), the PCR controls showed that the RNA was free of DNA contamination. 


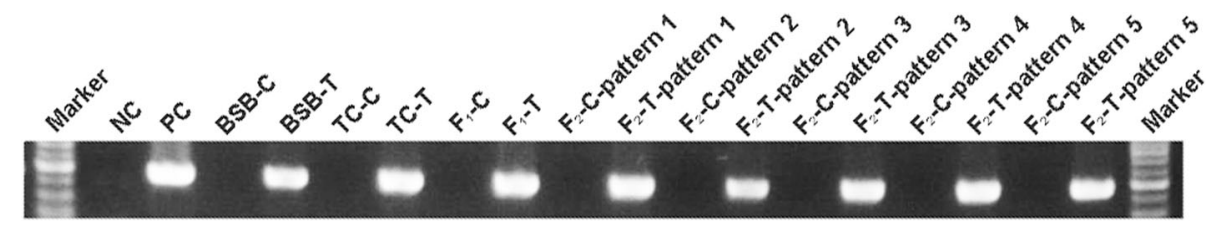

Fig. $2 P C R$ results of $C D N A$ and controls. Gel electrophoresis map of the $P C R$ results of $C D N A$ from $B S B, T C, F_{1}$ hybrids of $B S B \times T C$ and $F_{2}$ hybrids of $B S B \times$ TC. NC: negative control, PC: positive control. BSB-C: control in the BSB, BSB-T: treatment in the BSB. $F_{1}-C$ : the control in $F_{1}$ hybrids of BSB $\times T C, F_{1}-T$, the treatment in $F_{1}$ hybrids of $B S B \times T C$. $F_{2}-C$-pattern 1: the control of pattern 1 in $F_{2}$ hybrids of $B S B \times T C_{1}, F_{2}-T$-pattern 1: the treatment of pattern 1 in $F_{2}$ hybrids of BSB $\times$ TC. The other samples are named as the same rules. Note: For every pattern of each kind of fish, one sample was used to present

In the sequencing peak figures, homozygous samples have sequence traces with one peak, whereas heterozygous samples show two peaks. The two patterns are easily distinguishable. In the sequence traces of PCR products amplified with the primer pair $18 \mathrm{~S}$ P2F/P2R, only one peak is observed at the C308T SNP locus (the same SNP at position 40 of the $18 \mathrm{~S}$ rDNA amplified by the 18S P1F/P1R primer pair) in genomic DNA and cDNA of the 18S rRNA gene for both BSB and TC (Additional file 2A). In the F1 hybrids analyzed, the genotype for the C308T SNP is heterozygous, and expression of $18 \mathrm{~S}$ rRNA is also heterozygous with two peaks observed in the sequence traces for PCR products amplified from the cDNA of $18 \mathrm{~S}$ rRNA (Additional file 1B). Among the F2 hybrids, five patterns are observed. Pattern 1 inherits and expresses only the $45 \mathrm{~S}$ rRNA gene of BSB (Additional file 1C). Pattern 2 inherits the 45S rRNA gene from both BSB and TC, but only expresses the 45S rRNA of BSB. Pattern 3 inherits and expresses the 45S rRNA gene from both BSB and TC. Pattern
4 inherits the 45S rRNA gene from both BSB and TC, but only expresses the 45S rRNA gene of TC. Pattern 5 inherits and expresses only the $45 \mathrm{~S}$ rRNA gene of TC. A diagram of the genotype and expression patterns of $45 \mathrm{~S}$ rRNA genes in BSB and TC and their hybrids is shown in Fig. 3. The frequency distribution of the five different genetic expression patterns of $45 \mathrm{~S}$ rRNA gene in the F2 hybrids was showed in Table 1.

\section{Discussion}

Nucleolar dominance is a phenomenon observed in cells of interspecific hybrids in which nucleolus organizer regions (NORs) derived from one parental species are dominant over those derived from the other parent. Nucleolar dominance was first observed in hybrids of the plant genus Crepis, in which the NORs derived from only one species formed secondary constrictions [9]. In subsequent decades, nucleolar dominance has been described in hybrids of many plant genera, including Brassica [4] and Arabidopsis [17]. A

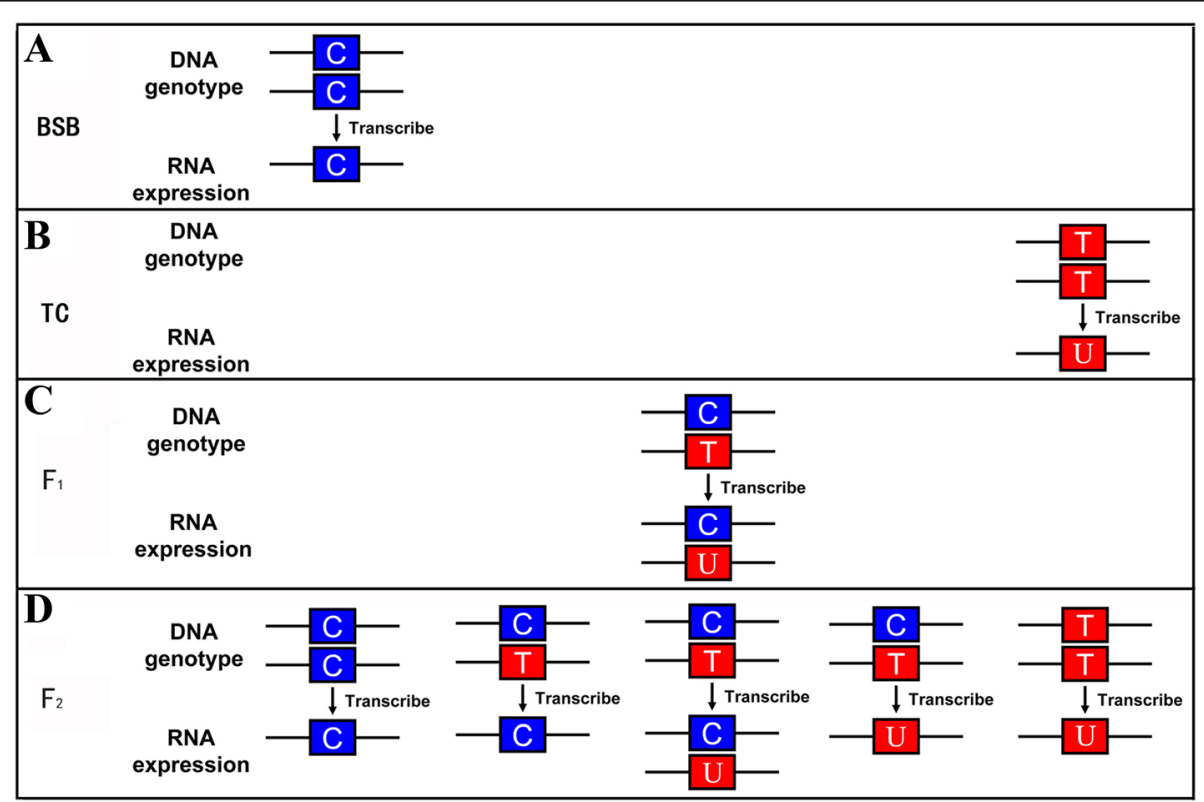

Fig. 3 The diagrammatic drawing of genotype and expression of $45 S$ rRNA gene. $\mathbf{a}$, $\mathbf{b}$ The genotype and expression of $45 S$ rRNA gene in BSB. The genotype and expression of $45 \mathrm{~S}$ rRNA gene in TC. $\mathbf{c}$ The genotype and expression of $45 \mathrm{~S}$ rRNA gene in $\mathrm{F}_{1}$ hybrids of BSB $\times$ TC. $\mathbf{d}$ The genotype and expression of $45 \mathrm{~S}$ rRNA gene in $\mathrm{F}_{2}$ hybrids of BSB $\times \mathrm{TC}$. Note: For every pattern of each kind of fish, one sample was used to present 
similar phenomenon occurs in hybrids of both Drosophila hybrids [18] and Xenopus hybrids, in which it has been confirmed that differential rRNA gene transcription is the basis of nucleolar dominance [19]. A form of nucleolar dominance is observed in human-mouse somatic cell hybrids [20]. However, in the present study, we observe that in the $\mathrm{F}_{1}$ hybrids of BSB $\times$ TC the $45 \mathrm{~S}$ rRNA genes of neither BSB nor $\mathrm{TC}$ are repressed. In the $\mathrm{F}_{2}$ hybrids, $45 \mathrm{~S}$ rRNA genes derived from one progenitor are silenced in some individuals, thus showing nucleolar dominance; while there are also some individuals that express $45 \mathrm{~S}$ rRNA genes derived from both parental species with no nucleolar dominance evident. These results indicate that nucleolar dominance patterns in the hybrid progeny of BSB and TC are different. Our results are partially consistent with nucleolar dominance research on allopolyploid Arabidopsis. In natural Arabidopsis suecica, an allotetraploid (amphidiploid) hybrid of Arabidopsis thaliana and Cardaminopsis arenosa, the A. thaliana rRNA genes are repressed. However, $A$. thaliana rRNA gene silencing is variable in synthetic $A$. suecica $\mathrm{F}_{1}$ hybrids. Two generations are needed for $A$. thaliana rRNA genes to be silenced in all lineages [17]. Variable rRNA gene silencing in A. suecica $\mathrm{F}_{1}$ hybrids suggests there is a stochastic component to the establishment of nucleolar dominance. Furthermore, completion of nucleolar dominance in the A. suecica $\mathrm{F}_{2}$ generation implies that silencing is cumulative and is not erased at meiosis. De novo cytosine methylation is a candidate DNA modification that might explain the stochastic onset and progressive establishment of nucleolar dominance [21-25] and is consistent with the depression of silenced rRNA genes by aza-dC (5-azadeoxycytidine). However, the number of generations needed to establish complete nucleolar dominance in hybrids of $\mathrm{BSB} \times \mathrm{TC}$ is unknown.

As reported [3], the nucleolar dominance is not random in genetic hybrids. Instead, it is always the rRNA genes from the same parent that are silenced. The choice mechanism is not based simply on the number of rRNA genes at an NOR, as NORs with fewer genes can be dominant over NORs with more rRNA genes. However, in this study, neither the set of $45 \mathrm{~S}$ rRNA genes from BSB nor that from TC is consistently silenced in the $F_{2}$ hybrid (Fig. 3). These results provide new insights into the phenomenon of nucleolar dominance in genetic hybrids. The question of why one set of 45S rRNA genes is not completely dominant over the other deserves further study.

There are $23.3 \%$ individuals in the $\mathrm{F}_{2}$ hybrids of BSB $\times$ TC only inherited the set of $45 \mathrm{~S}$ rRNA genes of one progenitor (Table 1). This has been shown by both ITS1 fragment amplification and sequencing of $18 \mathrm{~S}$ rDNA PCR products. Hybridization can result in alterations of in gene expression, chromosomal structure and genome size [26]. In the resynthesized hybrids and allopolyploids, loss of parental fragments and/or the appearance of novel fragments are commonly observed. Sequence elimination in the resynthesized allopolyploid wheat may account for a relatively large amount ( 14\%) of genome- or chromosomalspecific DNA sequences [27, 28]. In this study, all F1 hybrid individuals inherited the $45 \mathrm{~S}$ rDNA ITS1 sequences of both parents, which demonstrates the genetic hybridity of the $F_{1}$ offspring. Among F2 hybrids, $76.7 \%$ of the $\mathrm{F}_{2}$ hybrids inherited both parental types whereas $23.3 \%$ individuals lost the ribotype of one progenitor (BSB or TC) (Table 1), which indicates that $45 \mathrm{~S}$ rDNA sequence elimination may have occurred in the $F_{2}$ hybrids. These results support the theory that hybridization may lead to genetic change in the genomic DNA of the hybrids. We think that the genetics changes in the hybrids may have some relationship with the unique nucleolar dominance patterns in the hybrid lineage.

\section{Conclusions}

Nucleolar dominance patterns in intergeneric hybrids of $\mathrm{BSB}$ and TC are distinctive. Nucleolar dominance is not established in $F_{1}$ hybrids and is observed in some $F_{2}$ hybrids, indicating that genetic changes occur gradually in different generations in the hybrid lineage. In addition, neither the set of $45 \mathrm{~S}$ rRNA genes from $M$. amblycephala nor that from C. alburnus is consistently silenced in the $F_{2}$ hybrids, revealing that the nucleolar dominance is random in the $F_{2}$ hybrids of $M$. amblycephala and $C$. alburnus. These findings reveal new insights into the phenomenon of nucleolar dominance in genetics hybrids and provide a good model to study the molecular mechanism by which one progenitor's genes are selectively silenced.

\section{Methods}

\section{Study material and generation of hybrid populations}

Individuals of $\mathrm{BSB}, \mathrm{TC}, \mathrm{F}_{1}$ and $\mathrm{F}_{2}$ hybrid of $\mathrm{BSB} \times \mathrm{TC}$ are obtained from the Engineering Research Center of Polyploid Fish Breeding and Reproduction of the State Education Ministry, China, located at Hunan Normal University. The formation of the $F_{1}$ and $F_{2}$ hybrid of $\mathrm{BSB} \times \mathrm{TC}$ is described in our previous paper [14].

\section{Detection of hybridization}

To identify genetic markers to distinguish between BSB and TC, a pair of primers based on conserved regions of $18 \mathrm{~S}$ and $5.8 \mathrm{~S}$ ribosomal DNA (rDNA) in fish (P4F, $5^{\prime}-$ AGTCGTAACAAGGTTT CCGTAG-3'; P4A, 5' -ATC(A/ G)ATGTGTCCTGCAATTCAC-3') are designed and synthesized to amplify $45 \mathrm{~S}$ rDNA internal transcribed spacer 1 (ITS1) directly from genomic DNA. Total genomic DNA of $\mathrm{BSB}, \mathrm{TC}, \mathrm{F}_{1}$ and $\mathrm{F}_{2}$ hybrids of $\mathrm{BSB} \times \mathrm{TC}$ is extracted from liver tissue using a phenol/chloroform extraction method. PCR reactions are carried out in a volume of $50 \mu \mathrm{l}$ and contained approximately $50 \mathrm{ng}$ genomic DNA, $1.5 \mathrm{mM} \mathrm{MgCl}$, 
$250 \mathrm{mM}$ each dNTP, $0.4 \mathrm{mM}$ each primer, and $2.5 \mathrm{U}$ HS Taq polymerase (TaKaRa, Dalian, China). The thermal program consists of an initial denaturation step at $94{ }^{\circ} \mathrm{C}$ for 5 min, followed by 30 cycles $\left(94{ }^{\circ} \mathrm{C}\right.$ for $30 \mathrm{~s}, 56{ }^{\circ} \mathrm{C}$ for $30 \mathrm{~s}$, and $72{ }^{\circ} \mathrm{C}$ for $45 \mathrm{~s}$ ) and a final extension step at $72{ }^{\circ} \mathrm{C}$ for $10 \mathrm{~min}$. The PCR products are separated in a $2 \%$ agarose gel using TAE buffer. The DNA fragments are purified using a gel extraction kit (TaKaRa), an adenine residue is added to the end of the PCR products with DNA A-tailing kit (TaKaRa), and ligated into the pMD18-T vector (TaKaRa). The plasmids are transformed into Escherichia coli strain DH5a and purified, and the inserted DNA fragments are sequenced using an automated DNA sequencer (ABI PRISM 3730, Applied Biosystems, Carlsbad, CA, USA). To examine sequence homology and variation among the fragments amplified from BSB, TC, sequences are aligned using BioEdit [29] and Clustal W [30].

\section{Sequencing of $18 \mathrm{~S}$ rDNA}

To amplify the $18 \mathrm{~S}$ rDNA fragment directly from genomic DNA of BSB, TC and their hybrids, a pair of primers based on those described by Singh et al. [31] (18S P1F, 5'TTGGTGACTCTCGA TAACCTCGGGC-3'; 18S P1R, 5' CCTTGTTACGACTTTTACTTCCTC-3') are designed and synthesized. For sequencing, a second pair of primers (18S P2F, 5'-CTTGTCTCAA AGATTAAGCCATGC-3'; $18 \mathrm{~S}$ P2R, 5'-CTGCTGCCTTCCTTGGATGTGGT-3') based on the 45S sequence of common carp (GenBank, accession number: JN628435.1) are designed and synthesized to amplify the upstream sequences of $18 \mathrm{~S}$ rRNA genes containing the single nucleotide polymorphism (SNP) site confirmed with the $18 \mathrm{~S}$ P1F/P1R primer pair. PCR reactions are carried out in a volume of $50 \mu \mathrm{l}$ and contained approximately 50 ng genomic DNA, $1.5 \mathrm{mM} \mathrm{MgCl} 2,250 \mathrm{mM}$ each dNTP, $0.4 \mathrm{mM}$ each primer, and $2.5 \mathrm{U}$ HS Taq polymerase (TaKaRa). With the 18S P1F/P1R primer pair, the thermal program consist of an initial denaturation step at $94{ }^{\circ} \mathrm{C}$ for $5 \mathrm{~min}$, followed by 30 cycles $\left(94{ }^{\circ} \mathrm{C}\right.$ for $30 \mathrm{~s}, 56{ }^{\circ} \mathrm{C}$ for $45 \mathrm{~s}$, and $72{ }^{\circ} \mathrm{C}$ for $2 \mathrm{~min}$ ) and a final extension step at $72{ }^{\circ} \mathrm{C}$ for 10 min. With the $18 \mathrm{~S}$ P2F/P2R primer pair, the thermal program consist of an initial denaturation step at $94{ }^{\circ} \mathrm{C}$ for $5 \mathrm{~min}$, followed by 30 cycles $\left(94{ }^{\circ} \mathrm{C}\right.$ for $30 \mathrm{~s}, 56^{\circ} \mathrm{C}$ for $30 \mathrm{~s}$, and $72{ }^{\circ} \mathrm{C}$ for $45 \mathrm{~s}$ ) and a final extension step at $72{ }^{\circ} \mathrm{C}$ for $10 \mathrm{~min}$. The PCR products are separated in a $1.5 \%$ agarose gel using TAE buffer. The DNA fragments are sequenced using the method described above.

\section{Detection of single nucleotide polymorphism and $45 \mathrm{~S}$ rRNA expression}

Detection of species-specific rRNA genes and transcripts in interspecific hybrids between BSB and TC is limited by the low level of interspecific divergence in the 18S rRNA genes. On the basis of the $18 \mathrm{~S}$ rRNA gene sequences amplified by the $18 \mathrm{~S}$ P2F/P2R primer pair, a SNP at position
308 of the $18 \mathrm{~S}$ rRNA gene is fixed for cytosine in BSB (DDBJ accession number: AB860215) and thymine in TC (DDBJ accession number: AB860216).

Species-specific copies of rDNA and the corresponding rRNA transcripts are distinguished on the basis of the C308T SNP with direct sequencing of PCR products. Total RNA and genomic DNA are simultaneously isolated from single adult fish. 30 individuals of each kind of fish (including BSB, TC, $F_{1}$ and $F_{2}$ hybrids of $\mathrm{BSB} \times$ TC) are selected at random. Total RNA is isolated from liver tissue of different individuals with the Total RNA Isolation System (Omega Bio-Tek, Norcross, GA, USA). DNA is subsequently extracted using the TRI-Reagent (Omega Bio-Tek, Norcross, GA, USA) extraction protocol from the same sample. RNA is treated with DNase I (Amplification Grade, Invitrogen, Carlsbad, CA, USA) and first-strand cDNA is synthesized with Superscript III (Invitrogen) using an $18 \mathrm{~S}$ rRNA gene-specific primer (5'-TGCTGCCTTCCTTGGATGTG-3'). A 500 bp fragment containing the $\mathrm{C} 308 \mathrm{~T}$ polymorphism is amplified by PCR with the $18 \mathrm{~S}$ P2F/P2A primer pair. The cycling profile consist of $95{ }^{\circ} \mathrm{C}$ for $30 \mathrm{~s}, 56{ }^{\circ} \mathrm{C}$ for $30 \mathrm{~s}$, and $72^{\circ}$ $\mathrm{C}$ for $45 \mathrm{~s}$ for 30 cycles in a conventional thermal cycler. Identical conditions are used to amplify genomic DNA. PCR controls to detect contamination of RNA with genomic DNA are conducted for all samples. In these controls, DNase I-treated RNA is treated under the same conditions as the treatment samples, and only differed in that no transcriptase is added in the reverse transcription PCR (RT-PCR) process. Samples are considered free of contaminant DNA if PCR amplification failed. In some cases, contaminant genomic DNA is detected and a second DNase I treatment and RT-PCR are conducted. The PCR products are visualized in ethidium bromidestained agarose gels and purified using a gel extraction kit (TaKaRa) [30].

\section{Additional files}

\begin{abstract}
Additional file 1: The alignment of $18 \mathrm{~S}$ rDNA sequence of BSB and TC. The gap shows the single nucleotide polymorphism site between BSB and TC. (JPG $483 \mathrm{~kb}$ )

Additional file 2: The peak figures of the PCR products sequencing. A, The sequencing peak figures of the PCR products amplified from genomic and CDNA of $18 \mathrm{~S}$ rRNA gene in BSB and TC. B, The sequencing peak figures of the PCR products amplified from genomic and CDNA of $18 \mathrm{~S}$ rRNA gene in $\mathrm{F}_{1}$ hybrids of BSB $\times \mathrm{TC}$. $C$, The sequencing peak figures of the PCR products amplified from genomic and CDNA of $18 \mathrm{~S}$ rRNA gene in $F_{2}$ hybrids of BSB $\times$ TC. Only the SNP site and 2 upstream and downstream nucleotides are showed. Note: For every pattern of each kind of fish, one sample was used to present. (PPT $275 \mathrm{~kb}$ )
\end{abstract}

\section{Abbreviation}

BSB: Blunt snout bream; NORs: Nucleolus Organizer Regions; TC: Topmouth culter 


\section{Acknowledgements}

We thank Zhanzhou Yao for technical support with the experimental equipment.

\section{Funding}

This work is supported by the National Natural Science Foundation of China (Grant No. 31502159, 31210103918, 31430088), the Natural Science Foundation of Hunan Province (2015JJ3089), the key project of Hunan Science and Technology Office (2014NK2008), the Cooperative Innovation Center of Engineering and New Products for Developmental Biology of the Education Department of Hunan Province, and the construct program of the key discipline in Hunan province and China. The funding bodies play no role in the design of the study and collection, analysis and interpretation of data and in writing the manuscript.

\section{Availability of data and materials}

The sequencing data are deposited in NCBI (http://www.ncbi.n/m/. nih.gov/ nuccore) and is available from the authors. The fish cannot be made publicly available, because they are property of the Hunan Normal University.

\section{Authors' contributions}

JX, FH and KL carried out the molecular genetic studies, participated in the sequence alignment and drafted the manuscript. JX and KL participated in the design of the study and performed the statistical analysis. SL conceived of the study, and participated in its design and coordination and helped to draft the manuscript. WL contributed to raise the materials. All authors read and approved the final manuscript.

\section{Competing interests}

The authors declare that they have no competing interests.

\section{Consent for publication}

Not applicable.

\section{Ethics approval}

All experiments were approved by Animal Care Committee of Hunan Normal University and followed guidelines statement of the Administration of Affairs Concerning Animal Experimentation of China. All samples are raised in natural ponds and all dissections are performed under sodium pentobarbital anesthesia, and all efforts are made to minimize suffering [32].

This manuscript does not involve the use of any human data or tissue. So the consent to participate is not applicable.

\section{Received: 11 June 2016 Accepted: 25 November 2016}

Published online: 05 December 2016

\section{References}

1. Moss T, Langlois F, Gagnon-Kugler T, Stefanovsky V. A housekeeper with power of attorney: the rRNA genes in ribosome biogenesis. Cell Mol Life Sci. 2007;64(1):29-49.

2. McKeown PC, Shaw PJ. Chromatin: linking structure and function in the nucleolus. Chromosoma. 2009;118(1):11-23.

3. Tucker S, Vitins A, Pikaard CS. Nucleolar dominance and ribosomal RNA gene silencing. Curr Opin Cell Biol. 2010;22(3):351-6.

4. Chen ZJ, Pikaard CS. Epigenetic silencing of RNA polymerase I transcription: a role for DNA methylation and histone modification in nucleolar dominance. Genes Dev. 1997;11(16):2124-36

5. Lawrence RJ, Pikaard CS. Chromatin turn ons and turn offs of ribosomal RNA genes. Cell Cycle. 2004;3(7):880-3.

6. Earley K, Lawrence RJ, Pontes O, Reuther R, Enciso AJ, Silva M, Neves N, Gross M, Viegas W, Pikaard CS. Erasure of histone acetylation by Arabidopsis HDA6 mediates large-scale gene silencing in nucleolar dominance. Genes Dev. 2006:20(10):1283-93.

7. Preuss SB, Costa-Nunes $\mathrm{P}$, Tucker $\mathrm{S}$, Pontes $\mathrm{O}$, Lawrence RJ, Mosher $\mathrm{R}$, Kasschau KD, Carrington JC, Baulcombe DC, Viegas W, et al. Multimegabase silencing in nucleolar dominance involves siRNA-directed DNA methylation and specific methylcytosine-binding proteins. Mol Cell. 2008:32(5):673-84.

8. Pontvianne F, Blevins T, Chandrasekhara C, Feng W, Stroud H, Jacobsen SE, Michaels SD, Pikaard CS. Histone methyltransferases regulating rRNA gene dose and dosage control in Arabidopsis. Genes Dev. 2012;26(9):945-57.

9. Navashin M. Chromosome alterations caused by hybridization and their bearing upon certain general genetic problems. Cytologia. 1934;5(2):169-203.
10. McStay B. Nucleolar dominance: a model for rRNA gene silencing. Genes Dev. 2006:20(10):1207-14.

11. Preuss S, Pikaard CS. rRNA gene silencing and nucleolar dominance: insights into a chromosome-scale epigenetic on/off switch. Biochim Biophys Acta. 2007;1769(5-6):383-92

12. Flowers JM, Burton RS. Ribosomal RNA gene silencing in interpopulation hybrids of Tigriopus californicus: nucleolar dominance in the absence of intergenic spacer subrepeats. Genetics. 2006;173(3):1479-86.

13. Kwok P-Y, Duan S. SNP discovery by direct DNA sequencing. In: T Single Nucleotide Polymorphisms, vol. 212. 2002. p. 71-84.

14. Xiao J, Kang XW, Xie LH, Oin OB, He ZZL, Hu FZ, Zhang C, Zhao RR, Wang J, Luo KK, Liu Y, Liu SJ. The fertility of the hybrid lineage derived from female Megalobrama amblycephala × male Culter alburnus. Anim Reprod Sci. 2014; 151(1-2):61-70

15. Chen ZJ, Comai L, Pikaard CS. Gene dosage and stochastic effects determine the severity and direction of uniparental ribosomal RNA gene silencing (nucleolar dominance) in Arabidopsis allopolyploids. Proc Natl Acad Sci U S A. 1998;95(25):14891-6.

16. Pontes $O$, Lawrence RJ, Silva M, Preuss $S$, Costa-Nunes P, Earley K, Neves N, Viegas W, Pikaard CS. Postembryonic establishment of megabase-scale gene silencing in nucleolar dominance. PLoS One. 2007;2(11):e1157.

17. Chen ZJ, Comai L, Pikaard CS. Gene dosage and stochastic effects determine the severity and direction of uniparental ribosomal RNA gene silencing (nucleolar dominance) in Arabidopsis allopolyploids. Proc Natl Acad Sci. 1998; 95(25):14891-6.

18. Durica D, Krider H. Studies on the ribosomal RNA cistrons in interspecific Drosophila hybrids: I. Nucleolar dominance. Dev Biol. 1977;59(1):62-74.

19. Honjo T, Reeder RH. Preferential transcription of Xenopus laevis ribosomal RNA in interspecies hybrids between Xenopus laevis and Xenopus mulleri. J Mol Biol. 1973;80(2):217-28.

20. Croce CM, Talavera A, Basilico C, Miller OJ. Suppression of production of mouse $28 \mathrm{~S}$ ribosomal RNA in mouse-human hybrids segregating mouse chromosomes. Proc Natl Acad Sci. 1977:74(2):694-7.

21. Bestor TH, Chandler VL, Feinberg AP. Epigenetic effects in eukaryotic gene expression. Dev Genet. 1994;15(6):458-62.

22. Bird A. The essentials of DNA methylation. Cell. 1992;70(1):5-8.

23. Eden $\mathrm{S}, \mathrm{Cedar} \mathrm{H}$. Role of DNA methylation in the regulation of transcription. Curr Opin Genet Dev. 1994:4(2):255-9.

24. Razin A, Cedar H. DNA methylation and genomic imprinting. Cell. 1994; 77(4):473-6.

25. Martienssen RA, Richards EJ. DNA methylation in eukaryotes. Curr Opin Genet Dev. 1995:5(2):234-42

26. Baack EJ, Rieseberg LH. A genomic view of introgression and hybrid speciation. Curr Opin Genet Dev. 2007:17(6):513-8.

27. Feldman M, Liu B, Segal G, Abbo S, Levy AA, Vega JM. Rapid elimination of low-copy DNA sequences in polyploid wheat: a possible mechanism for differentiation of homoeologous chromosomes. Genetics. 1997;147(3):1381-7.

28. Shaked H, Kashkush K, Ozkan H, Feldman M, Levy AA. Sequence elimination and cytosine methylation are rapid and reproducible responses of the genome to wide hybridization and allopolyploidy in wheat. Plant Cell. 2001; 13(8):1749-59.

29. Hall TA. BioEdit: a user-friendly biological sequence alignment editor and analysis program for Windows 95/98/NT. In: Nucleic acids symposium series 1999. p. $95-8$.

30. Thompson JD, Higgins DG, Gibson TJ. CLUSTAL W: improving the sensitivity of progressive multiple sequence alignment through sequence weighting, position-specific gap penalties and weight matrix choice. Nucleic Acids Res. 1994;22(22):4673-80.

31. Singh M, Kumar R, Nagpure NS, Kushwaha B, Gond I, Lakra WS. Chromosomal localization of 185 and $5 \mathrm{~S}$ rDNA using FISH in the genus Tor (Pisces, Cyprinidae). Genetica. 2009:137(3):245-52

32. Zhang C, Ye LH, Chen YY, Xiao J, Wu YH, Tao M, Xiao YM, Liu SJ. The chromosomal constitution of fish hybrid lineage revealed by 55 rDNA FISH. BMC Genet. 2015:16:140. 